\title{
Subsidies and Awards in Movie Production*
}

\author{
Betty Agnani and Henry Aray ${ }^{\dagger}$ \\ University of Granada
}

December 2008

\begin{abstract}
This article analyzes the effect of subsidies and awards on the Spanish motion picture industry. We estimate a Cobb-Douglas production function using regional data, showing that it exhibits constant returns to scale and that awards positively affect movie production, while subsidies have no effect. In fact, awards affect the productivity of the sector since they allow for an increase in the output, which is not explained by an increase in inputs.
\end{abstract}

Key words: Movie production, awards, panel data.

JEL Classification: Z11, C23.

*The authors gratefully acknowledge financial support from the Spanish Ministry of Education and Science and the Junta de Andalucia through Projects SEJ200762081/ECON and SEJ-2547, respectively.

†Corresponding Author: Universidad de Granada. Facultad de Ciencias Económicas y Empresariales. Dpto. de Teoría e Historia Económica. Campus de la Cartuja S/N, Granada 18011, Spain. e-mails: bagnani@ugr.es, haray@ugr.es. Phone: +34958241937. Fax: +3495849995. 


\section{Introduction}

In this article we examine the Spanish motion picture industry. Specifically, we are interested in testing what effects subsidies and awards may have on Spanish movie production. On the one hand, it is widely known that, in general, the European movie industry is financially supported by governments. However, the objective of subsidies does not seem to be clearly settled. Subsidies can increase the number of films and hence achieve higher levels of production and employment in the sector, they can increase the quality of the films or they can make films more socially and culturally focused. On the other hand, in spite of the importance normally attributed to cinematography awards, there are no articles in the relevant literature that quantitatively measure the impact of awards on movie production in a country with a relative small industry such as Spain.

Intuition suggests that awards should have a positive effect on production. Awards could be interpreted as a positive expectation in general by motion picture producers in a country with a relatively small industry. Domestic and foreign demand for Spanish films might be expected to rise the more awards the industry wins, which could in turn imply an increase in box office takings for Spanish films and higher profits for domestic producers. However, the effect of subsidies is not clear a priori, since they can be positive if the objective is to maintain production and employment, but negative if the objective is to improve the quality and focus of the films.

The interest and novelty of the present article lies in the fact that it is the first article to relate subsidies and awards to movie production. To some extent, our work could be related to Jansen (2005) who studies the relationship between subsides and profits for the German film industry and the works of Nelson et al. (2001) and Deuchert et al. (2005) who studied the effect of Oscar nominations and awards on the financial success of a movie.

The rest of the article is organized as follows. The econometric model and estimation issues are presented in Section 2. Conclusions are drawn in Section 3.

\section{Econometric Estimations}

We consider an input augmenting production function model. Therefore, let $Y_{t}$ be the production of feature films at each period $t$ given by a Cobb-Douglas 
function as

$$
Y_{t}=\left(A_{t} K_{t}\right)^{\alpha}\left(A_{t} L_{t}\right)^{\beta}
$$

$K_{t}$ is the physical capital, $L_{t}$ is the labor input and $A_{t}$ is an augmenting input factor specified as

$$
A_{t}=\theta S_{t}^{\gamma} P_{t-1}^{\delta} \varepsilon_{t}
$$

where $\theta$ is a constant term, $S_{t}$ is the total subsidy given by the central government to the production of feature films in period $t$ and $P_{t-1}$ is the number of international awards given to the whole industry in year $t-1$. We assume that the effect of awards on movie production has a lag of one year since it is natural to expect that this effect is not conveyed in the current period but takes some time. $\varepsilon_{t}$ is an iid random disturbance.

A similar specification of the production function in (1) was used by Bergström (2000) to study the effect of subsidies on the performance of firm productivity. However, this specification has a drawback in that it considers the labor factor simply as the number of workers or working hours, but ignores the skills and capabilities of the workers. In order to overcome this drawback we consider a measure of human capital, $N_{t}$, defined following Hall and Jones (1999)

$$
N_{t}=\sum_{j=1}^{3} L_{t, j} e^{\phi_{j} x_{j}},
$$

where $L_{t, j}$ is the number of workers with educational level $j$ in the movie production industry in period $t$ and with $j=1,2,3$ accounting for primary, secondary and superior, respectively. $x_{j}$ is the years of each educational level ${ }^{1}$ and $\phi_{j}$ is the rate of return to schooling in Spain according to Lassibille and Navarro (1998). Therefore, instead of (1), we consider

$$
Y_{t}=\left(A_{t} K_{t}\right)^{\alpha}\left(A_{t} N_{t}\right)^{\beta}
$$

When attempting to perform the econometric estimation we face two problems. On the one hand, data on subsidies are only available for a short period of time. In order to take advantage of the scarce data available and

\footnotetext{
${ }^{1}$ We assume the middle point of each range of years of schooling, which are assumed to be constant over time.
} 
to obtain as many observations as possible, we have to use regional data on movie production and panel data regression. Therefore, we write the production function referred to the Spanish region $i$ as follows,

$$
Y_{i t}=A_{i t}^{\alpha+\beta} K_{i t}^{\alpha} N_{i t}^{\beta}
$$

with

$$
\begin{aligned}
N_{i t} & =\sum_{j=1}^{3} L_{i t, j} e^{\phi_{j} x_{j}} \\
A_{i t} & =\theta_{i} S_{t}^{\gamma} P_{t-1}^{\delta} \varepsilon_{i t}
\end{aligned}
$$

On the other hand, data for physical and human capital inputs are not available. Therefore, we have to rely on proxies. For the physical capital in region $i$, we use the number of firms involved in the production of at least one film in period $t$. In this sense, each firm is considered as one unit of physical capital. Regarding human capital, we have regional-level data on the number of workers in the cultural sector ${ }^{2}$, which could not be a good proxy for $L_{i t}$ in the cinema sector. Therefore, we calculate the number of workers in the cinema sector in each region, $L_{i t, j}$, using the proportion of workers in the cinema industry at each educational level over the total workers in the cultural sector in the country ${ }^{3}$.

Taking the natural logarithm of (3) and considering the specification of $A_{i t}$, we obtain the equation to be estimated

$$
\operatorname{Ln}\left(Y_{i t}\right)=\phi_{i}+\lambda_{1} \operatorname{Ln}\left(S_{t}\right)+\lambda_{2} \operatorname{Ln}\left(P_{t-1}\right)+\alpha \operatorname{Ln}\left(K_{i t}\right)+\beta \operatorname{Ln}\left(N_{i t}\right)+\mu_{i t}
$$

with

$$
\begin{aligned}
\phi_{i} & =(\alpha+\beta) \operatorname{Ln} \theta_{i} \\
\lambda_{1} & =(\alpha+\beta) \gamma \\
\lambda_{2} & =(\alpha+\beta) \delta \\
\mu_{i t} & =\operatorname{Ln}\left(\varepsilon_{i t}\right)
\end{aligned}
$$

\footnotetext{
${ }^{2}$ The cultural sector includes employees in museums, theaters, cinema (both exhibition and production), radio, television, etc.

${ }^{3} \mathrm{We}$ assume that this proportion remains constant across regions.
} 
Data from the Spanish Ministry of Culture were used. We consider annual data for the 2002-2007 period. We have included regions that produced films during the entire period under study. Taken together, these regions account for more than 95 percent of movie production in the whole country. The regions are: Andalusia, Catalonia, Galicia, Madrid, Navarre, the Basque Country and Valencia. As the available data on subsidies is given in nominal values, the real value, $S_{t}$, referred to euros in the year 2000, is obtained using the consumer price index of leisure and culture provided by the Spanish Statistics Institute (INE).

Table 1 presents the panel data regression of (4) using the least squares dummy variable (LSDV) approach to estimate the fixed effects $\left(\phi_{i}\right)$ which are not shown. The estimations are robust to heteroskedasticity using a covariance matrix $\grave{a}$ la White (1980). The results show that all the coefficients associated to the explanatory variables are positive. Notice that physical and human capital inputs are significant at the $5 \%$ level.

Our first finding is that the production function of the Spanish motion picture industry exhibits constant returns to scale. This is due to the fact that we test the hypothesis of constant return to scale, $H_{1}$ ( $p$-values in parentheses), and are unable to reject it.

The second finding concerns the subsidies which have no effect on movie production. An explanation could be that the main objective of subsidies during the period under study was to improve the quality and focus of the films instead of stimulating production. In fact, Act 15/2001 alleges arguments on cultural grounds to guarantee public funds for the production of Spanish films.

The third finding is that awards do have a significant positive effect at the $5 \%$ level. Hence, the more awards won by the Spanish industry in international film contests, the higher the production in the sector. This third result supports our initial intuition since awards could be considered good signals for the movie industry. In fact, this could be interpreted as a positive expectation in general by motion picture producers in a country with a relatively small industry. Domestic and foreign demand for Spanish films might be expected to rise, which could imply an increase in box office takings for Spanish films and higher profits for domestic producers.

Notice that our results not only suggest that awards positively affect movie production, but also, and perhaps much more importantly, they affect the productivity of the sector since they allow for an increase in output, which is not explained by an increase in inputs. 
Finally, Table 1 also shows tests of joint significance of the fixed effects $\mathrm{H}_{2}$ and homogenous effects $\mathrm{H}_{3}$. Both are rejected ( $p$-values in parentheses). Therefore, Spanish regions exhibit heterogeneous fixed effects in movie production which could be interpreted as permanent differences in productivity in movie production across regions.

\section{Conclusions}

This paper analyzes motion picture production in Spain. Specifically, we test the effect of subsidies and awards on movie production. We use regional data and panel data regression. We assume a Cobb-Douglas production and find that awards have a significant positive effect on movie production. However, we find no effect of subsidies. According to the evidence, movie production in Spain exhibits constant returns to scale and there are differences in productivity across regions. 


\section{References}

[1] Bergström, F. (2000). Capital Subsidies and the Performance of Firms. Small Business Economics, 14, 183-193.

[2] Deuchert, E., Adjamah, K., and F. Pauly. (2005). "For Oscar Glory or Oscar Money". Journal of Cultural Economics, 29, 159-176.

[3] Hall, R. E. and C. I. Jones. (1999). Why do Some Countries Produce so Much More Output per Worker than Others?. The Quarterly Journal of Economics, 114, 1, 83-116.

[4] Jansen, C. (2005). The Performance of German Motion Pictures, Profits and Subsidies: Some Empirical Evidence. Journal of Cultural Economics 29, 191-212.

[5] Lassibille, G. and L. Navarro Gómez. (1998). The Evolution of Returns to Education in Spain 1980-1991. Education Economics, 6, 1, 3-9.

[6] Nelson, R.A., Donihue, R., Waldman, D.M. and C. Wheaton. (2001). What's an Oscar Worth?. Economic Inquiry, 39 (1), 1-16.

[7] White, H. (1980). A Heteroskedasticity-Consistent Covariance Matrix Estimator and A Direct Test for Heteroskedasticity. Econometrica, 48, 817838. 
Table 1. Panel Data Regression with Fixed Effects

\begin{tabular}{llc}
\hline \hline & Coefficients & Standard Errors \\
\hline $\operatorname{Ln}\left(S_{t}\right)$ & 0.0298 & 0.0921 \\
$\operatorname{Ln}\left(P_{t-1}\right)$ & $0.5335 *$ & 0.1951 \\
$\operatorname{Ln}\left(K_{i t}\right)$ & $0.7234^{*}$ & 0.0541 \\
$\operatorname{Ln}\left(N_{i t}\right)$ & $0.3422^{* *}$ & 0.1422 \\
\hline$R^{2}$ & 0.9859 & \\
$D W$ & 2.2904 & \\
\hline$H_{1}$ & 0.2618 & \\
& $(0.6089)$ & \\
$H_{2}$ & 67.7379 & \\
& $(0.0000)$ & \\
$H_{3}$ & 56.9975 & \\
& $(0.0000)$ & \\
\hline$*(* *)$ Significant at $1 \%(5 \%)$ & \\
\hline
\end{tabular}

